\title{
The Use Of User Experience (UX) And Multimedia Project Management (MPM) To Produce Learning-Module Videos For Autism Children: A Post-Study Focus Group Session With Autism Caretakers
}

\author{
Zaidatol Haslinda Abdullah Sani ${ }^{1 *}$, Dinna N. Mohd Nizam², Carolyn Salimun ${ }^{3}$ \\ 1,2,3,4 UX Research Lab, Faculty of Computing and Informatics, University Malaysia Sabah, Malaysia \\ 33carolyn@ums.edu.my
}

Article History: Received: 11 January 2021; Accepted: 27 February 2021; Published online: 5 April 2021

\begin{abstract}
Autism is a condition where one has challenges in controlling their social skills and behaviours. Autism affects their communications with people surrounding them. WHO reports one in every 160 children has autism. Interventions are needed by the autism community to assists them in teaching the autism students and managing the autism centers. User Experience (UX) and Multimedia Project Management (MPM) are used to produce learning-module videos for autism children. An 8-week field study of a summative evaluation on the use of the video was conducted. A post-study focus group discussion was then discussed with three caretakers regarding the use of the video for 1) the students learning skills and for 2 ) the caretakers to teach the students. The findings show using MPM and UX for developing videos for autism children is positive for both questions. However, further investigation on the learning capability of the autism students can be explored.
\end{abstract}

Keywords: autism, focus group, multimedia project management, user experience.

\section{INTRODUCTION}

Autism Spectrum Disorder (hereafter "autism") is a condition where one has challenges in controlling their social skills and behaviours [1]. Autism can be classified into mild or severe disorder in which both need a caretaker. People with autism have problems communicating, especially in expressing themselves, either verbal or non-verbal. This leads to having a problem for other people to understand their needs, wants, and concerns. A caretaker is the one taking care of the autism people. A caretaker would have special-needs training which is a practice in dealing with people with autism. WHO reported one in every 160 children has autism [2]. There is no known cause of autism and no cure for autism. However, research has shown that interventions combining with ongoing therapies can positively lead to having an independent, happy, and productive autitic person [3, 4].

User Experience (hereafter "UX") is the overall experience of a user after using such technology [5]. One main idea of UX is by including users throughout the whole development of the technology. This includes by involving the users in investigating the problems, designing the technology, and evaluating the technology. UX fits well in all typical software development: software development life cycle, agile, scrum or other development lifecycles. A huge number of research has proved that that using UX in developing technology can give positive results in particular on its effectiveness, efficiency, and ease of use piece to the users [6-8].

Multimedia Project Management (hereafter "MPM") is a practice of managing a project to ensure its success in reaching the project goals at a specified time [9, 10]. A typical MPM consists of four phases. In each phase, there are deliverables that need to be completed and succeeded prior to moving to the next phase. MPM helps the project manager to monitor the overall progress of the project. Each phase consists of a milestone. This provides a good basis for control of the project. This also provides confidence in managing the project. The first phase is Project Initiation. This is the beginning of the project, which can make a difference in the project's success or failure. In this phase, a deep understanding of the problem is needed. The second phase is the Pre-production. This phase consists of gathering the raw materials before any development is conducted. Proper design i.e., storyboards of the multimedia, should be ready at this stage. The third phase is the Production. This phase if where you get your hands dirty in producing multimedia. The workable or executable version of your multimedia should be ready at this stage. The last phase is the Post-production. Both alpha and beta testing should be conducted to ensure the multimedia fits the requirements, as stated in the Project Initiation phase.

Reviewing the research in autism, education, management, and technology, little work has been done in combining these three areas in particular in understanding the autism caretakers' perspective while taking care of the autism students. To investigate this matter, we partnered with UMSKAL Autism Development Centre (UADC) and students from Multimedia Technology Programme (MTP), Universiti Malaysia Sabah. UADC requested ten learning-module videos to be viewed daily by their students. Further explanations of these 
The Use Of User Experience (UX) And Multimedia Project Management (MPM) To Produce

Learning-Module Videos For Autism Children: A Post-Study Focus Group Session With Autism

Caretakers

learning-modules is in Section 2, below. Students from MTP produced the videos using UX and MPM, similarly, further explanations in Section 2. A focus group discussion was then conducted to discuss the use of the videos with a group of caretakers from UADC.

The order of this paper is as such: Section 2 presents the model of combining UX and MPM in producing learning-module videos for UADC, Section 3 provides the method for the focus group discussions, Section 4 presents the results and discussions, and lastly, Section 5 concludes the paper.

\section{LEARNING-MODULE VIDEO PRODUCTION USING USER EXPERIENCE (UX) AND MULTIMEDIA PROJECT MANAGEMENT (MPM)}

UMSKAL Autism Development Centre (UADC) located in Labuan, Malaysia was founded in 2016. Currently, UADC has more than 20 mild-autism students registered at the centre. The students range from preschoolers and are not more than 12 years old. The students are grouped into a few factors: their age and the level of their mild autism. Further classification of the mild autism will not be discussed in this paper. UADC requested ten learning-module videos (hereafter "modules") to be viewed daily by their students. Each module consists of steps that need to be easily followed by the students. The steps are simple and straightforward. These are the main factors in dealing with people with autism. Figure 1 shows an example of some steps of Arriving at School Module.

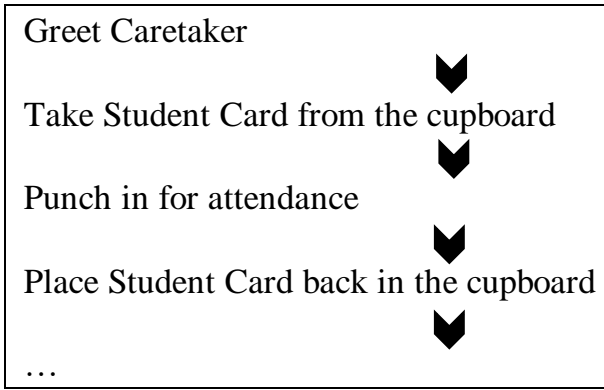

Figure 1: Some steps of Arriving at School Module, adapted from UADC

Currently, the modules are printed and compiled in a file only. As for the example above, in Arriving at School Module, the caretakers will wait in front of the gate and perform the steps with the students each day. There will be cases where students might forget the steps. If there are any newcomers, he / she will observe how the other students are doing the steps and then follow. Other modules include Physical Activity Module, Morning Walk Module, Eating with Cutlery Module, Eating with Hand Module, Toilet Module and a few others.

The UADC management is interested in exploring technology interventions to encourage the students to remember these steps. It is knowns the people with autisms are observers and tend to follow what other people will do. Thus, producing videos were suggested.

\subsection{COMBINING UX AND MPM TO PRODUCE THE LEARNING-MODULE VIDEOS}

50 students from Multimedia Technology Programme (MTP), Universiti Malaysia Sabah were grouped into 10 groups with five students per group. Each group was assigned to produce one learning-module video. Based on UX, we included UADC, as our user, throughout the whole MPM production of the videos. It should be noted that it is quite hard to interview the autism students per se. Thus, as been conducted by other autism research, interviewing the caretakers is the closest person that could understand people with autism [11,12]. The duration of the MPM was 25 weeks. All phases of MPM were completed within the timeframe. Table 1 shows the combination of MPM and UX in producing each learning-module video.

Table 1: The combination of MPM and UX in producing the learning-module videos

\begin{tabular}{|l|l|l|}
\hline MPM & UX & $\begin{array}{l}\text { Duration } \\
\text { (Week No.) }\end{array}$ \\
\hline $\begin{array}{l}\text { Project } \\
\text { Initiation \& } \\
\text { Pre-production }\end{array}$ & $\begin{array}{l}\text { Interview with the } \\
\text { caretakers of UADC to get } \\
\text { further understanding } \\
\text { about: } \\
\text { - the module } \\
\text { - the requirement of the }\end{array}$ & Week 3 \\
\hline
\end{tabular}




\begin{tabular}{|c|c|c|}
\hline & $\begin{array}{l}\text { video } \\
\text { - the do's and don'ts for } \\
\text { people with autism } \\
\text { - and other requirements } \\
\text { needed }\end{array}$ & \\
\hline Production & $\begin{array}{l}\text { The production of the } \\
\text { learning-module videos by } \\
\text { the MTP students }\end{array}$ & $\begin{array}{l}\text { Week } 4- \\
\text { Week } 10\end{array}$ \\
\hline Post-production & $\begin{array}{l}\text { 1. Formative evaluation } \\
\text { - Each group presented } \\
\text { their video to the } \\
\text { caretakers } \\
\text { - The caretakers } \\
\text { evaluated the usability of } \\
\text { the video } \\
\text { 2. Re-production of the } \\
\text { video base on the } \\
\text { comments received from } \\
\text { the caretakers and experts } \\
\text { 3. Summative evaluation } \\
\text { - For this interest of this } \\
\text { paper, we focused on one } \\
\text { learning-module only } \\
\text { - The caretakers run the } \\
\text { video to the autism } \\
\text { students, daily } \\
\text { - The caretakers were } \\
\text { asked to observe the } \\
\text { students' attitude on their } \\
\text { leaning interest after } \\
\text { watching the video, and } \\
\text { the caretakers perspective } \\
\text { while taking care of the } \\
\text { autism students in using } \\
\text { the video } \\
\text { 4. Post-study focus group } \\
\text { session on the summative } \\
\text { evaluation }\end{array}$ & $\begin{array}{l} \\
\text { Week } 12 \\
\text { Week } 15 \\
\text { Week } 16 \\
\text { Week } 24\end{array}$ \\
\hline
\end{tabular}

This paper is interested in presenting point no. 4 of the post-production phase. The method of the focus group is presented in the next section.

\section{METHOD}

The focus group discussion (hereafter "discussion") was about 1) the autism students' attitude on learning interest while watching the video, 2) the caretakers' perspective while taking care of the autism students in using the video. One discussion with three participants was conducted. The moderator was experienced at focus group moderations. The moderator also took notes on each point given by the participants. To suit the participants, the discussion was conducted in Malay.

\subsection{Participant}

The participation was voluntary. The participants were caretakers of UADC. Each caretaker had work for more than one year with UADC. There were two women and one man. All participants also participated in the Project Initiation and Pre-production phase of the MPM.

\subsection{Material and Equipment}


The discussion questions were post-study questions. The questions included about the autism students' attitude on learning interest while watching the video and the caretakers' perspective while taking care of the autism students in using the video.

\subsection{Procedure}

The discussion was conducted at UADC. During the discussion, they were other classes for the autism students, but other caretakers handled them. We did not interrupt any ongoing classes. The discussion lasted for nearly 1 hour.

The moderator started by introducing the objectives and procedures of the discussion. There was no consent form signed. The moderator started asking questions related to the discussion. A fair amount of time was given for each participant to share their views. At the end of the discussion, the moderator highlighted the key points noted by the participants. No cash rewards were given as the participation was voluntary. Lastly, the moderator debriefed and thank them.

\subsection{Data Analysis}

A content analysis [13] was conducted on the notes. The notes were read and re-read to identify the topics in related to the students' attitude on learning interest while watching the video and the caretakers' perspective while taking care of the autism students in using the video. All notes were translated into English. An open coding technique [14] was done until appropriate topics emerged. To establish inter-coder reliability of the categorization, a second coder went through all of the topics and any disagreements were resolved.

\section{RESULT AND DISCUSSION}

Overall, the focus group discussion found the use of UX and MPM in producing video is positive. Although the participants had no idea of UX and MPM, the participants repeatedly commented on, especially in making sure the video really suited the students. Some of the comments is as such:

- "it was different before now it's better for the student" p1

- "that's why it's important to show to us first" $p 3$

In regard to the students' attitude on learning while watching the videos also brings positive results. However, it is noted that further investigation could be done to really investigate the capability of the students to learn without the caretakers to guide them. Some of the comments were:

- "this is something new they enjoyed watching it" $p 2$

- "they do remember when we keep on showing the video again and again" $p 3$

- "we did not really measure before and after we only observe in general maybe in the future we can study this" $p 1$

In regard to the caretakers' perspective while taking care of the autism students in using the video, the participants like the idea. All of them commented positively in combining technology intervention in assisting them in educating the students. The participants also gave other interventions that can be done apart from videos to assist them in teaching. Some of the comments were:

- "the video is interesting because it's a different way for us to teach the students" $p 3$

- "the video is good but I also have another idea why not you do a system that can play back the sounds of the words I mean when you click on that word the system will pronounce it back we need to teach the students to talk properly" $p 1$

\section{CONCLUSION}

This paper presented an overview of the development of a video production for learning-modules for UMSKAL Autism Development Centre (UADC). We combined User Experience (UX) and Multimedia Project Management (MPM) to produce the videos. Based on UX, we included UADC, as our user, in each phase of MPM.

This paper also presented the result of a focus group discussion in regards to 1) the autism students' attitude on learning interest while watching the video, and 2) the caretakers' perspective while taking care of the autism students in using the video. The results of the focus groups were positive in both questions. However, it should be 
noted that further investigation on such learning intervention can be done to investigate the capability of the students to learn without having the caretakers to guide them.

\section{ACKNOWLEDGEMENT}

The authors would like the thank UMSKAL Autism Development Centre (UADC) for their dedication in this research. We would also like to thank the students of Multimedia Technology Programme (MTP), Universiti Malaysia Sabah, to produce wonderful videos for the autism students. We would also like to thank our reviewers for their comments.

\section{REFERENCES}

1. Lord, C., Brugha, T. S., Charman, T., Cusack, J., Dumas, G., Frazier, T., ... \& Taylor, J. L. (2020). Autism spectrum disorder. Nature reviews Disease primers, 6(1), 1-23.

2. WHO (2019), Autism Spectrum Disorder. Viewed on 9th July https://www.who.int/news-room/fact-sheets/detail/autism-spectrum-disorders

3. Hedges, S. H., Odom, S. L., Hume, K., \& Sam, A. (2018). Technology use as a support tool by secondary students with autism. Autism, 22(1), 70-79.

4. Kinsella, B. G., Chow, S., \& Kushki, A. (2017). Evaluating the usability of a wearable social skills training technology for children with autism spectrum disorder. Frontiers in Robotics and AI, 4, 31.

5. Benyon, D. (2019). Designing User Experience: a guide to HCI, UX and interaction design. Pearson UK.

6. Abdullah Sani, Z.H., \& Petrie, H. (2017). Evaluation of an app to support healthy living by older adults. Electronic Visualisation and the Arts (EVA 2017), 1-14.

7. Harutyunyan, N., \& Riehle, D. (2019, January). User experience design in software product lines. In Proceedings of the 52nd Hawaii International Conference on System Sciences.

8. Seidler, C., Aydogdu, S., \& Schick, B. (2019, July). User Experience in Real Test Drives with a Camera Based Mirror-Influence of New Technologies on Equipping Rate for Future Vehicles. In International Conference on Human-Computer Interaction (pp. 270-281). Springer, Cham.

9. England, E., \& Finney, A. (2007). Managing interactive media: Project management for Web and digital media. Pearson Education.

10. Rada, R. (2012). Interactive media. Springer Science \& Business Media.

11. Nichols, C., Block, M. E., Bishop, J. C., \& McIntire, B. (2019). Physical activity in young adults with autism spectrum disorder: Parental perceptions of barriers and facilitators. Autism, 23(6), 1398-1407.

12. Aguiar, M. C. M. D., \& Pondé, M. P. (2019). Parenting a child with autism. Jornal Brasileiro de Psiquiatria, 68(1), 42-47.

13. Krippendorff K. Content analysis: An introduction to its methodology. Sage publications; 2018 May 9.

14. Steenkamp A, Raisinghani MS. Research methodologies, innovations, and philosophies in software systems engineering and information systems. Mora M, Gelman O, editors. Hershey, PA: IGI Global; 2012 Feb 29. 